\title{
DERECHO Y POLÍTICAS AMBIENTALES EN LA COMUNIDAD VALENCIANA
}

\author{
MARTA OLLER Rubert \\ Profesora contratada doctora de Derecho Administrativo \\ Universitat Jaume I
}

Sumario: 1. Ley 5/2017, de 10 de febrero, de Pesca Marítima y Acuicultura de la Comunitat Valenciana. 2. Decreto 49/2017, de 31 de marzo, del Consell, de modificación del Decreto 97/2010, de 11 de junio, del Consell, por el que se regula el ejercicio del derecho de acceso a la información ambiental y de participación pública en materia de medio ambiente.

\section{LEY 5/2017, DE 10 DE FEBRERO, DE PESCA MARÍTIMA Y ACUICULTURA DE LA COMUNITAT VALENCIANA}

Con fecha en el DOCV de 13 de febrero de 2017, se publicó la Ley 5/2017, de 10 de febrero, de la Generalitat, de Pesca Marítima y Acuicultura de la Comunitat Valenciana, que vino a derogar la Ley 9/1998, de 15 de diciembre, de Pesca Marítima, y la Ley 2/1994, de 18 de abril, sobre defensa de los recursos pesqueros, así como aquellas disposiciones de igual o inferior rango que se opongan a lo dispuesto en la nueva norma. Una ley, pues, que regula de manera unitaria cuestiones antaño dispersas y que, además, amplía su regulación sobre la base de las nuevas competencias asumidas por la Comunidad Valenciana tras la reforma de su Estatuto en 2006. Una ley que, como se desprende de su preámbulo y de su articulado, busca regular el desarrollo de la pesca marítima y en aguas interiores, del marisqueo y de la acuicultura, así como la comercialización de los productos provenientes de aquellos, pero bajo los postulados de la protección de los recursos naturales, como se encarga de fijar el artículo 4, que, entre otras finalidades, recoge la de la conservación de los recursos biológicos marinos, la protección de las zonas biológicamente sensibles —declarándolas zonas protegidas-y la explotación sostenible de los recursos pesqueros y de la acuicultura, para lo que se hace referencia al necesario equilibrio entre la perspectiva ambiental, la económica y la social. 
La perspectiva ambiental se observa en diversos aspectos de la Ley. Así, en su capítulo I, dedicado a la "pesca profesional", al enumerar las modalidades de pesca aptas en la Comunidad Valenciana, destaca que las allí enumeradas arrastre de fondo, cerco, artes menores y palangre de superficie- pueden limitarse o ampliarse bajo el prisma del principio de precaución ecosistémico (art. 7.2). Asimismo, en el título III, que regula el marisqueo, se contempla como límite de estas actividades que se trate de especies en régimen de protección especial (art. 22). Una de las novedades más relevantes es la regulación en el título IV de las actividades destinadas a la extracción o recogida de algas y sargazos, puesto que dicha actividad, en efecto, puede causar graves daños a los ecosistemas del litoral. Por ello, el artículo 23 determina que su extracción deberá realizarse por medios que no perturben el medio ambiente (art. 23), de la misma forma que se tendrá en cuenta el principio de conservación y precaución de los ecosistemas para establecer los instrumentos, las zonas y los períodos de actividad en que se puede llevar a cabo. Por otro lado, en el título $\mathrm{V}$ se regula la cría o cultivo de organismos acuáticos -acuicultura- y se establece que las zonas destinadas a estas prácticas deben atender a criterios de sostenibilidad, por lo que se obliga a que en el procedimiento de autorización para realizar dichas actividades se dé audiencia a las asociaciones de defensa del medio ambiente (art. 26).

El título VI, "De la conservación y explotación sostenible de los recursos pesqueros", es quizás el más orientado a preservar el medio ambiente, ya que su capítulo II contiene medidas destinadas, en concreto, a proteger y conservar los recursos, destacando la declaración de "zona protegida de interés pesquero", que supone una limitación en relación con la extracción de fauna y flora marina. Esta declaración le compete al Consell, que deberá escuchar, entre otros, a las asociaciones en defensa del medio ambiente (art. 36). Junto con la anterior, también se regulan las llamadas "reservas marinas de interés pesquero".

En cuanto a la regulación del sector pesquero del título VIII, se incluyen entre las medidas de fomento de la flota pesquera de la Comunidad Valenciana "la reducción del impacto ambiental de la flota pesquera" (art. 53). 
Finalmente, debe destacarse el título XI, sobre el "régimen sancionador", pues otorga fuerza a las previsiones ambientales que se pretenden con la nueva Ley. En ese sentido, debemos fijarnos en la tipificación de las infracciones y sanciones previstas en la norma; así, se tipifica como infracción leve "la captura de especies protegidas" (art. 78.6) y como infracción muy grave "la realización de actividades que causen o que por sus características puedan causar daños graves a los recursos marinos en las zonas declaradas protegidas" (art. 80.1.d). En cuanto a las sanciones, se graduarán atendiendo a la trascendencia y repercusión del perjuicio causado al medio o a los recursos marinos, entre otros criterios (art. 82). Es destacable que, en el caso de que se impongan multas, el importe se destinará íntegramente a la consecución, entre otros, de objetivos de conservación, protección y regeneración de los recursos pesqueros.

2. DECRETO 49/2017, DE 31 DE MARZO, DEL CONSELL, DE MODIFICACIÓN DEL DECRETO 97/2010, DE 11 DE JUNIO, DEL CONSELL, POR EL QUE SE REGULA EL EJERCICIO DEL DERECHO DE ACCESO A LA INFORMACIÓN AMBIENTAL Y DE PARTICIPACIÓN PÚBLICA EN MATERIA DE MEDIO AMBIENTE

El objeto de esta norma es establecer el órgano competente para la resolución de solicitudes de información ambiental realizadas en virtud del derecho de acceso a la información ambiental en el ámbito de la Comunidad Valenciana, tras la modificación de la estructura orgánica de la Conselleria de Agricultura, Medio Ambiente, Cambio Climático y Desarrollo Rural realizada por el Decreto 158/2015, de 18 de septiembre. De esta forma, el artículo 9 establece que el Centro de Información y Documentación Ambiental (CIDAM) será el órgano que desempeñará las funciones en materia de información y participación ambiental. Así, el CIDAM seguirá elaborando la propuesta de resolución sobre las solicitudes de información ambiental, siendo la persona titular de la Dirección General de Prevención de Incendios Forestales —a la que está adscrito el CIDAM desde la reforma del 2017-quien finalmente las resolverá. 
Sumari: 1. Llei 5/2017, de 10 de febrer, de Pesca Marítima i Aqüicultura de la Comunitat Valenciana. 2. Decret 49/2017, de 31 de març, del Consell, de modificació del decret 97/2010, d'11 de juny, del Consell pel qual es regula el dret d'accés a la informació ambiental i de participació pública en matèria de medi ambient.

\section{LLEI 5/2017, DE 10 DE FEBRER, DE PESCA MARÍTIMA I AQÜICULTURA DE LA COMUNITAT VALENCIANA}

Amb data en el DOCV de 13 de febrer de 2017 es va publicar la Llei 5/2017, de 10 de febrer, de la Generalitat, de Pesca Marítima i Aqüicultura de la Comunitat Valenciana que va venir a derogar la Llei 9/1998, de 15 de desembre de pesca marítima i la Llei 2/1994, de 18 d'abril, sobre defensa dels recursos pesquers, així com aquelles disposicions d'igual o inferior rang que s'oposin al que es disposa en la nova norma. Una Llei doncs, que regula de manera unitària, qüestions antany disperses i que a més, amplia la seva regulació, sobre la base de les noves competències assumides per la Comunitat Valenciana després de la reforma del seu Estatut en 2006. Una llei que com es desprèn del seu preàmbul i del seu articulat pretén regular el desenvolupament de la pesca marítima, en aigües interiors, del marisqueig i de les aqüicultura, així com la comercialització dels productes provinent d'aquelles, però sota els postulats de la protecció dels recursos naturals, com s'encarrega de fixar l'art.4 que, entre altres finalitats, recull la de la conservació dels recursos biològics marins, la protecció de les zones biològicament sensibles, declarant-les zones protegides, l'explotació sostenible de recursos pesquers i de l'aqüicultura, i per a això es fa referència al necessari equilibri entre la perspectiva ambiental, econòmica $i$ social.

La perspectiva ambiental s'observa en diversos aspectes de la Llei. Així, en el seu Capítol I dedicat a la "pesca professional" en enumerar les modalitats de pesca aptes a la Comunitat Valenciana destaca que les allí enumerades, arrossegament de fons, cèrcol, arts menors i palangre de superfície, poden limitar-se o ampliar-se, sota el prisma del principi de precaució ecosistèmic (art. 7.2). Així mateix, en el Títol III que regula el Marisqueig es contempla com a límit d'aquestes activitats que es tracti d'espècies en règim de protecció especial (art.22). Una de les novetats mes rellevants, és la regulació en el Títol IV de les activitats destinades a l'extracció o recollida d'algues i sargassos, ja 
que aquesta activitat, en efecte, pot causar greus danys als ecosistemes del litoral. Per això, l'art.23 determina que l'extracció de les mateixes haurà de realitzar-se per qualsevol mitjà que no pertorbi el medi ambient (art.23), de la mateixa forma que el principi de conservació i precaució dels ecosistemes serà condicionant pel establiment de quins instruments, zones i períodes d'activitat en què es pot practicar les mateixes. D'altra banda, en el Títol V es regula la cria o cultiu d'organismes aquàtics -aqüicultura- i una vegada mes, s'observa com les zones destinades a aquestes pràctiques han d'atendre a criteris de sostenibilitat, per a això s'obliga al fet que en el procediment d'autorització per realitzar aquestes activitats, se de audiència a les associacions en defensa del medi ambient (art.26).

El títol VI "De la conservació i explotació sostenible dels recursos pesquers" és potser el mes orientat a preservar el medi ambient, ja que el seu capítol II conté mesures destinades, en concret, a protegir i conservar els recursos, destacant la declaració de "zona protegida d'interès pesquers" que suposa una limitació en relació amb les extracció de fauna i flora marina. Aquesta declaració li competeix al Consell que haurà de sentir, novament, entre uns altres, a les associacions en defensa del medi ambient (art.36). Juntament amb l'anterior, també es regula les anomenades "reserves marines d'interès pesquer".

Quant a la regulació del sector pesquer del títol VIII s'inclouen entre les mesures de foment de la flota pesquera de la Comunitat Valenciana "la reducció de l'impacte ambiental de la flota pesquera" (art.53).

Finalment ha de destacar-se el Títol XI de el "règim sancionador" doncs és a partir del mateix que s'atorga força a les previsions ambientals que es pretenen amb la nova Llei. En aquest sentit, hem de fixar-nos en la tipificació de les infraccions i sancions previstes en la norma i podem citar la tipificació com a infracció lleu de "la captura d'espècies protegides" (art.78.6) i com a infracció molt greu "la realització d'activitats que causin o que per les seves característiques puguin causar danys greus als recursos marí a les zones declarades protegides" (art.80.1.d). Quant a les sancions es graduaran atenent a la transcendència i repercussió del perjudici causat al mitjà 0 als recursos marins, entre altres criteris (art.82). És destacable que en el cas que s'imposin 
multes l'import es destinés íntegrament a la consecució, entre uns altres, d'objectius de conservació, protecció i regeneració dels recursos pesquers.

\section{DECRET 49/2017, DE 31 DE MARÇ, DEL CONSELL, DE MODIFICACIÓ DEL DECRET 97/2010, D'11 DE JUNY, DEL CONSELL PEL QUAL ES REGULA EL DRET D'ACCÉS A LA INFORMACIÓ AMBIENTAL I DE PARTICIPACIÓ PÚBLICA EN MATÈRIA DE MEDI AMBIENT.}

La raó d'aquesta norma és establir l'òrgan competent per a la resolució de sol-licituds d'informació ambiental exercides en virtut del dret d'accés a la informació ambiental en l'àmbit de la Comunitat Valenciana, després de la modificació de l'estructura orgànica de la Conselleria d'Agricultura, Medi ambient, Canvi Climàtic i Desenvolupament Rural realitzada pel Decret 158/2015, de 18 de setembre. D'aquesta forma s'estableix en l'art.9 que el Centre d'Informació i Documentació Ambiental (CIDAM) serà l'òrgan que exercirà les funcions en matèria d'informació i participació ambiental. Així, el CIDAM seguirà elaborant la proposta de resolució sobre les sol-licituds d'informació ambiental sent el competent per resoldre la persona titular de I'òrgan directiu al que estigui adscrit el CIDAM que fins a la reforma del 2017 era la Subsecretària competent de la Conselleria. Com hem assenyalat després de la reforma estructural aquest òrgan és la Direcció General de Prevenció d'Incendis Forestals, incorporada en 2015. 